\author{
International Journal of Innovative Research in \\ Electrical, Electronics, Instrumentation and Control Engineering
}

Vol. 7, Issue 5, May 2019

\title{
Modelling and Control of Hybrid Stepper Motor using LabVIEW
}

\author{
Pavithra $D^{1}$, Rini Raj $A^{2}$, Sudhanthira $\mathbf{P}^{3}$, Gopalakrishnan $\mathbf{R}^{4}$ \\ Student, Electrical and Eletronics Engineering, K.Ramakrishnan College of Engineering, Trichy, India ${ }^{1,2,3}$ \\ Assistant Professor, Electrical and Eletronics Engineering, K.Ramakrishnan College of Engineering, Trichy, India ${ }^{4}$
}

\begin{abstract}
In recent years motors have been playing key role in many applications viz, industrial, transport, military etc. The stepper motor has varied applications from low level to high torque applications. The main disadvantage of the stepper motor is to control it for its Step angle and its ripples. In our paper, we have modeled and developed a prototype which is simulated using MATLAB and the motor is triggered and controlled using LabVIEW and Arduino. The MATLAB platform helps to develop the controlled parameter for LabVIEW, which in turn provide controlled, nonharmonic output.
\end{abstract}

Keywords: Stepper Motor, MATLAB, LabVIEW, Ardunio

\section{INTRODUCTION}

Despite strong competition from servo systems, hybrid stepper motors remain the preferred solution for many applications as they can provide accurate position and speed control in an open-loop system. However, they provide a challenge to the motor designer in two respects. Firstly, they are a truly 3-d device, the main flux taking both radial and axial paths, and secondly, they are designed to operate under highly saturated conditions in order to achieve a competitive torque per unit volume [1]. A simple FOC without DQ transformation is developed for the position tracking of PMSMs [5]. An approach for applying EKF to a drive-in order to estimate a hybrid stepper motor's position when the drive is connected to the motor by long cables is developed [6]. A stepper motor of required torque is excited with digital input pulse, and it rotates through a particular angle. In addition to this, open loop control of motor further makes it effortless to control its movement. However, closed control becomes essential when acceleration with variable loads is involved [1]. Stepper motor can accept digital signal directly, without having D/A converter, so that computer control of stepper motor is very convenient.

At present, the acceleration and deceleration process is using linear law to control .In this method, pulse frequency changes have a constant acceleration, but the torque of stepper motor with the increase in pulse frequency decreased, So the linear law speed control curve is not the ideal rising and falling speed control curve [2].Because of high precision of positioning ,no cumulative error and low cost of the driver ,stepper motor are widely used in some automation system .In addition to the development of modern industry ,there are more and more requirements of precision and high speed performance of using the stepper motor as driver system. The control mode of stepper motor is thus gradually developed into closed loop control and adopts high efficient controller to get better performance as comparing to open loop control [3].

Stepper motors are also known as step motors, are used in industrial robots, computer numerical control machines,3D printing machines, instruments used in laser and optics, varies medical robots and space robots.

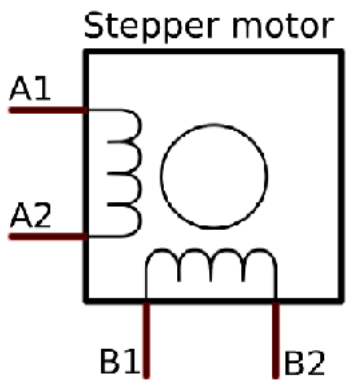

Figure (1.1) Cross section of hybrid stepper motor 


\section{International Journal of Innovative Research in Electrical, Electronics, Instrumentation and Control Engineering}

Vol. 7, Issue 5, May 2019

The advantages of using stepping motors in open-loop positioning control systems don't exclude certain limits of frequency at motor acceleration and deceleration. The improvement of stepping motor dynamic performances is achieved by its control based on variable frequency upon a given law.

A. Motor specifications

Table 1 specifications of hybrid stepper motor

\begin{tabular}{|l|l|}
\hline DESCRIPITION & RATINGS \\
\hline Step angle (degree) & 1.8 \\
\hline Rated current (A) & 1.7 \\
\hline Phase resitance (ohm) & 1.2 \\
\hline Phase Inductance (mH) & 1.8 \\
\hline Holding Torque & 28 \\
\hline Detente Torque & 1.6 \\
\hline Motor weight & 220 \\
\hline
\end{tabular}

\section{MATHEMATICAL MODELLING}

A Mathematical model is a description of a system using mathematical concepts. A model may help to explain a system in a better way to investigate the effect of different components and to make predictions about behavior. Dynamic models are typically represented as differential equations or difference equations.

\section{A. Voltage Equation}

The voltage equation of the phase $\mathrm{k}$ is,

$\mathrm{U}_{\mathrm{K}=} \mathrm{R}_{\mathrm{K}} \mathrm{I}_{\mathrm{K}}+\mathrm{d} \varphi_{\mathrm{K} / \mathrm{d} t}$

$\mathrm{K}=1,2,3 \ldots$

$\varphi_{\mathrm{K}}$ - total flux that flow through phase $\mathrm{K}$

$\varphi_{\mathrm{K}}=\sum_{\mathrm{J}=1}^{\mathrm{M}} \mathrm{L}_{\mathrm{K} \mathrm{j}} \mathrm{I}_{\mathrm{j}}$

$\mathrm{L}_{\mathrm{K} \text { _ }}$ static self inducing of phase $\mathrm{k}$

$\mathrm{U}_{\mathrm{K}}=\mathrm{R}_{\mathrm{K}} \mathrm{I}_{\mathrm{K}+\sum}{ }^{\mathrm{m}}{ }_{\mathrm{j}=1} \mathrm{~L}_{\mathrm{Kj}} \mathrm{di}_{\mathrm{j}} / \mathrm{dt}+\mathrm{dl}_{\mathrm{kj}} / \mathrm{d} \Theta \mathrm{de} / \mathrm{dt} \mathrm{i}_{\mathrm{j}}$

B. Torque equation

The torque equation of motor is given by,

$\mathrm{J} \mathrm{d}^{2} \mathrm{\theta} / \mathrm{dt}^{2}+\mathrm{B} \mathrm{de} / \mathrm{dt}+\mathrm{T}_{\mathrm{r}=\mathrm{T}_{\mathrm{e}}}$

$\mathrm{J}$ - total moment of inertia

$\mathrm{B}-$ coeffeicient of viscous friction

$\mathrm{T}_{\mathrm{r}}$ - Load torque

$\mathrm{T}_{\mathrm{e}}$ - Electromagnetic Torque

1

III. WORKING PRINCIPLE

A. System Identification with Matlab Tool.

In this paper, the motor equations of torque, voltage are given to the matlab simulation model of hybrid stepper motor. These equations are modeled using simulation. The input values of motor parameter are fed to the simulation model which gives the transfer function of proposed model using system identification tool. The obtained transfer function is fed to the PID tuning which turns the transfer function for PID values. After tuning the controlled response of PID values are obtained. The controlled PID values are given to the LabVIEW, the controlled output is obtained.

Without using MATLAB Simulink controller, the simulation output of LabVIEW produces some perturbations and damping. By using modern simulation method, the motor parameters can be controlled in LabVIEW through obtained transfer function. Whereas in conventional method the derivation of motor parameter is complex. In MATLAB using the system identification tool the transfer unction is obtained. The input values of motor parameter are fed to the simulation model and they are obtained to the system identification tool which gives the transfer function of the proposed model. 
International Journal of Innovative Research in Electrical, Electronics, Instrumentation and Control Engineering

Vol. 7, Issue 5, May 2019

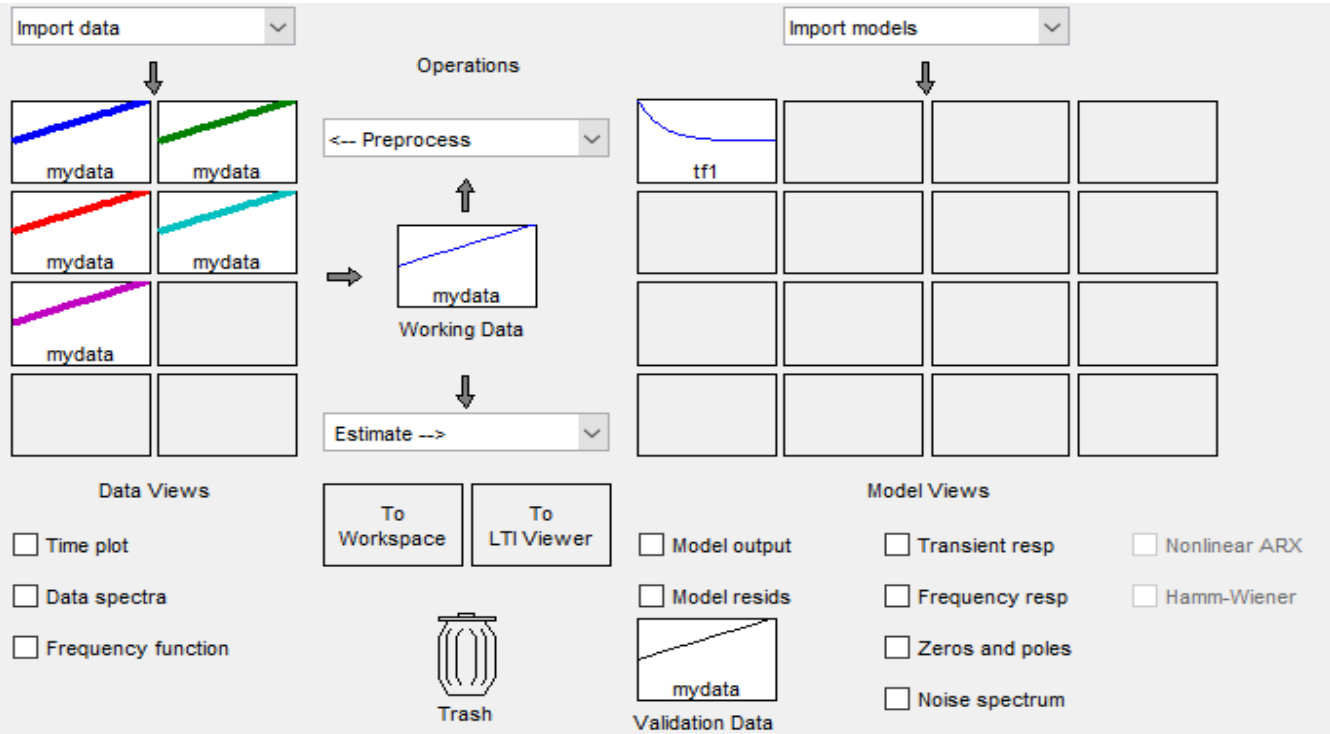

Figure (1.2) System identification tool

B. PID Tuning-Controller Design

The obtained transfer function from the system identification tool box is fed to the PID tuning tool, which turns the transfer function for PID values. Initially the PID response is obtained for undamped system.
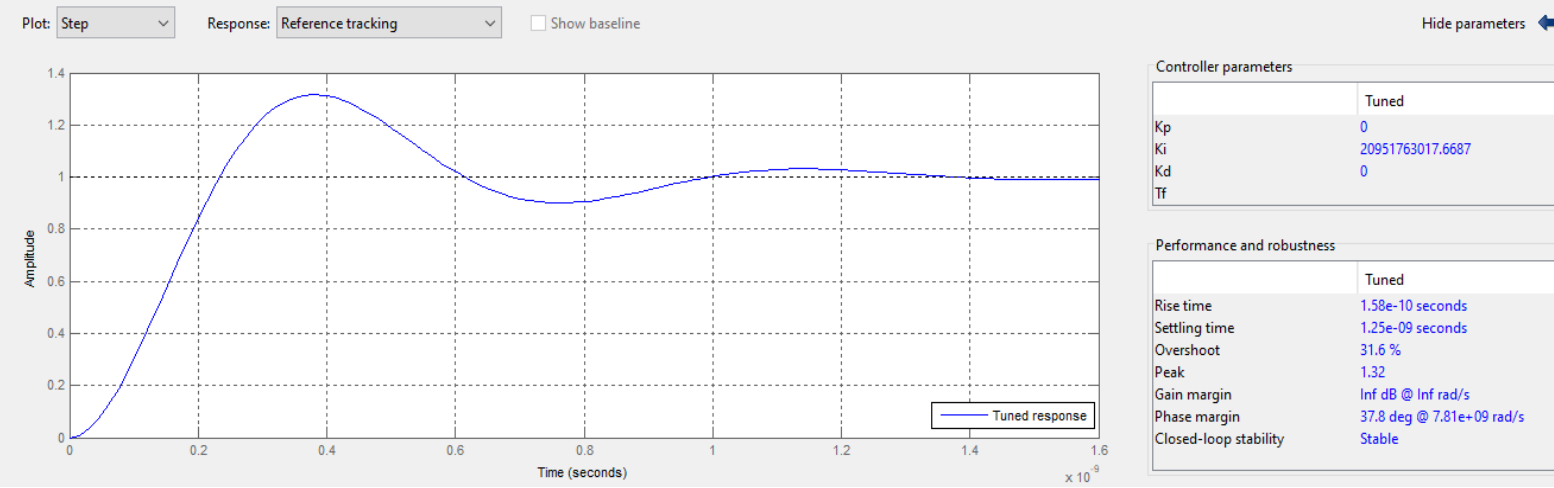

Figure (1.3) Response with natural tuning

C. PID Tuning -Controlled Design

In the above, the output response of the motor has some damping. So, we are going for further tuning. Which gives us the improved response.

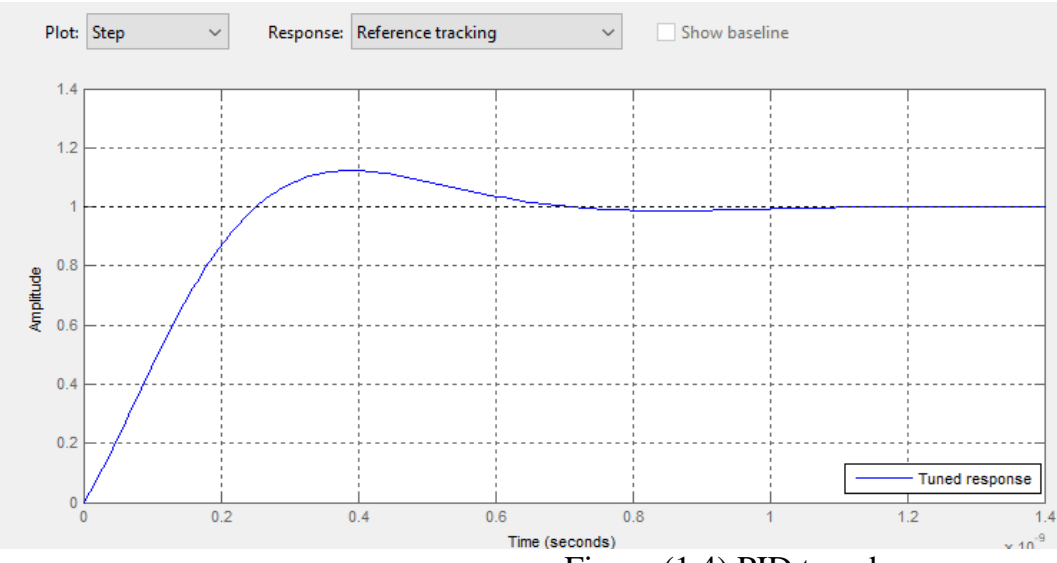

\begin{tabular}{|c|c|}
\hline \multirow{2}{*}{\multicolumn{2}{|c|}{ Controller parameters }} \\
\hline & \\
\hline & Tuned \\
\hline Kp & 1.014 \\
\hline $\mathrm{Ki}$ & 19395940888.8439 \\
\hline Kd & 0 \\
\hline \multicolumn{2}{|l|}{ If } \\
\hline \multicolumn{2}{|c|}{ Performance and robustness } \\
\hline & Tuned \\
\hline Rise time & $1.87 \mathrm{e}-10$ seconds \\
\hline Settling time & $6.4 \mathrm{e}-10$ seconds \\
\hline Overshoot & $12.2 \%$ \\
\hline Peak & 1.12 \\
\hline Gain margin & Inf $\mathrm{dB} @ \mathrm{NaN} \mathrm{rad} / \mathrm{s}$ \\
\hline Phase margin & $60 \mathrm{deg} @ 7.81 \mathrm{e}+09 \mathrm{rad} / \mathrm{s}$ \\
\hline Closed-loop stability & Stable \\
\hline
\end{tabular}

Figure (1.4) PID tuned response

After further tuning the PID values are obtained for controlled response. 
International Journal of Innovative Research in Electrical, Electronics, Instrumentation and Control Engineering

Vol. 7, Issue 5, May 2019

\section{MATLAB OUTPUT}

In matlab the output has been get through system identification tool. the figure (1.5) shows the without controller in matlab simulink.

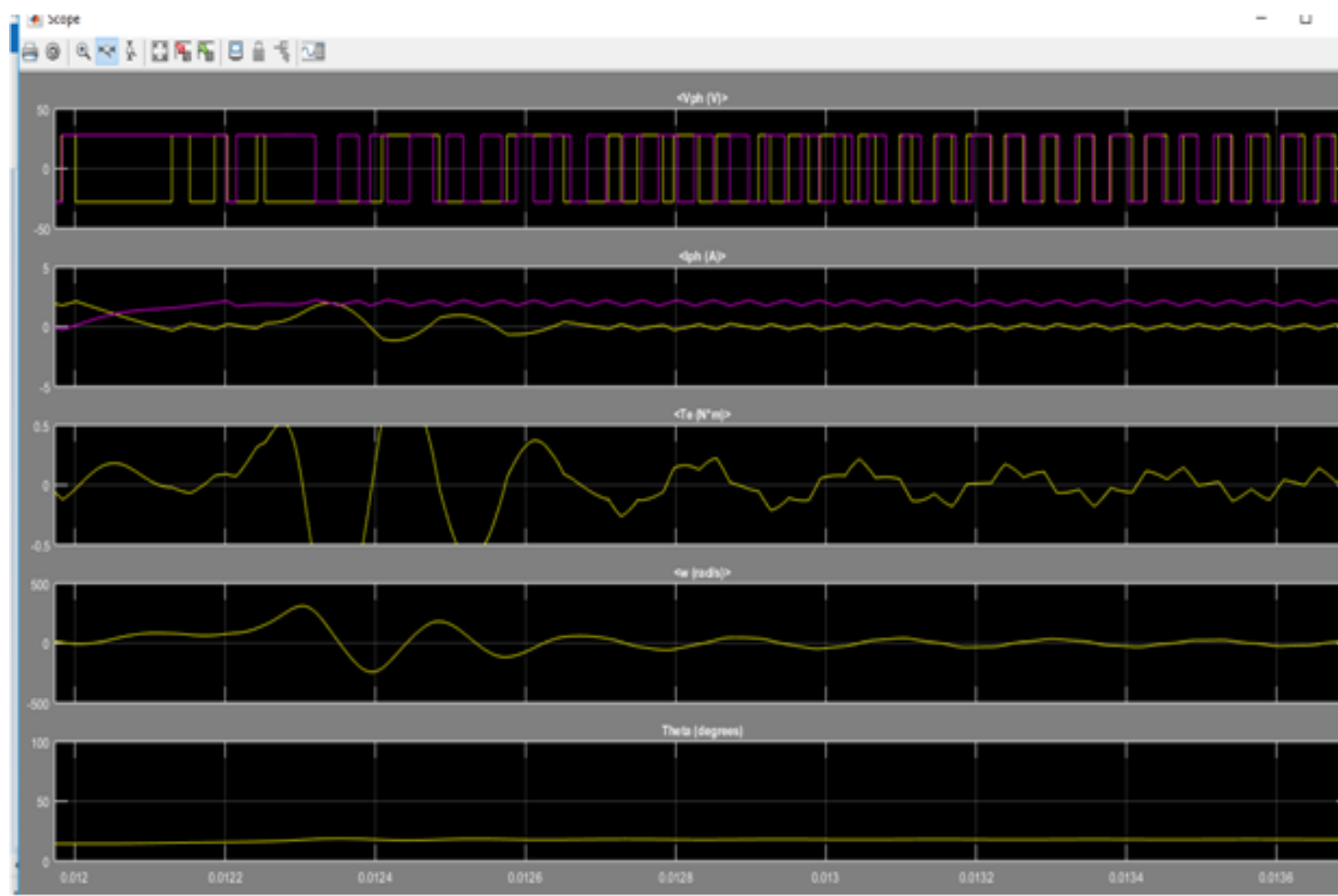

Figure (1.5) MATLAB Simulink Output Without Controller

Later tuning, the output has been through system identification tool. The figure (1.6) shows the with controller in matlab simulink.

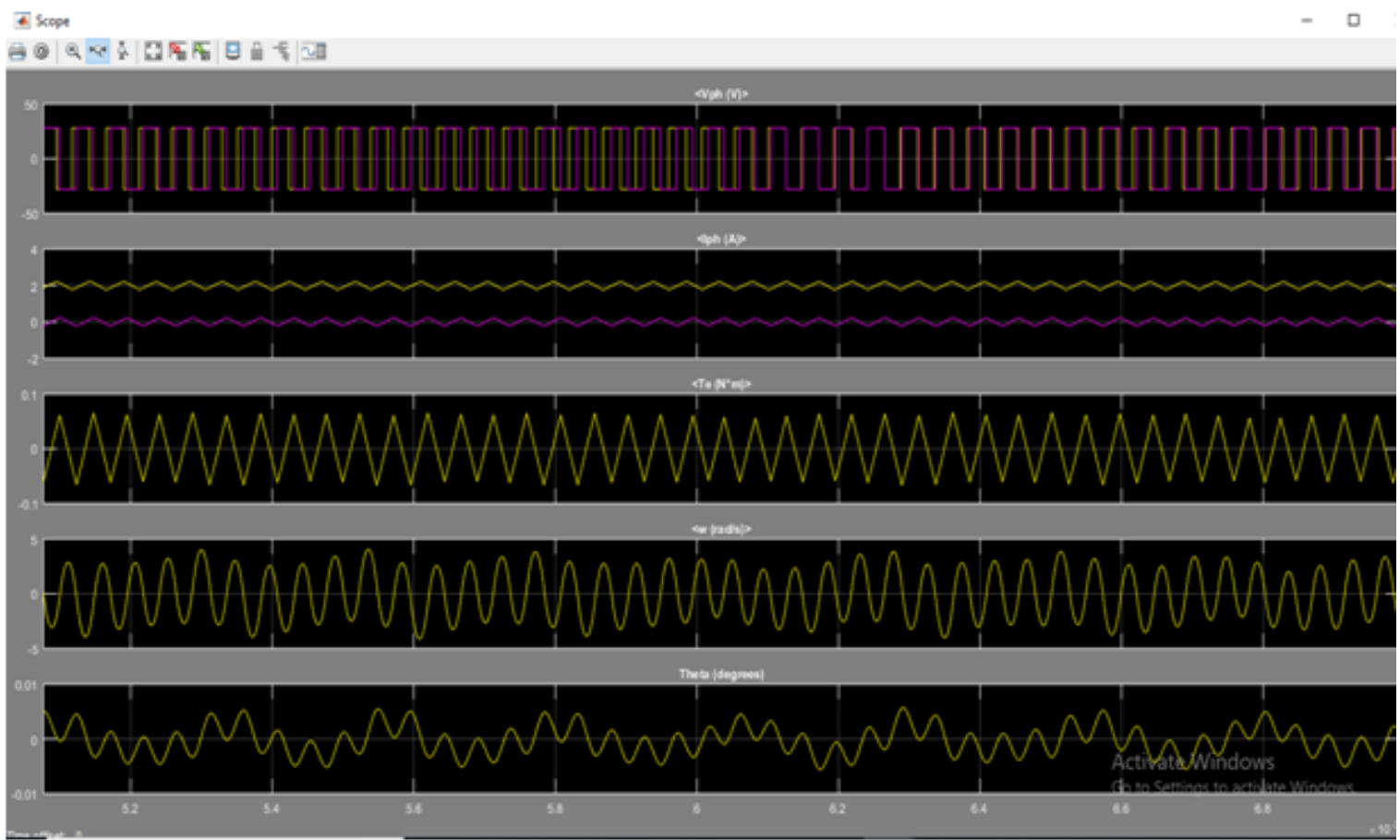

Figure (1.6) Matlab Simulink Output With Controller 
International Journal of Innovative Research in Electrical, Electronics, Instrumentation and Control Engineering

Vol. 7, Issue 5, May 2019

\section{HARDWARE AND SIMULATION}

The Hybrid stepper motor is taken for the proposed paper. The input 12volt supply is given to the motor and Arduino is interfaced with LabVIEW and the digital sequenced pulses for each phase of the motor is given through the motor driver.

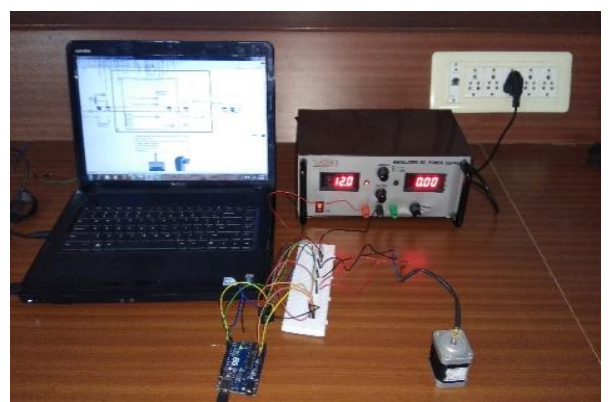

Figure (1.7) Hardware Setup Model

The pluses can be changed in the contol panel and motor output can be controlled using in labview.

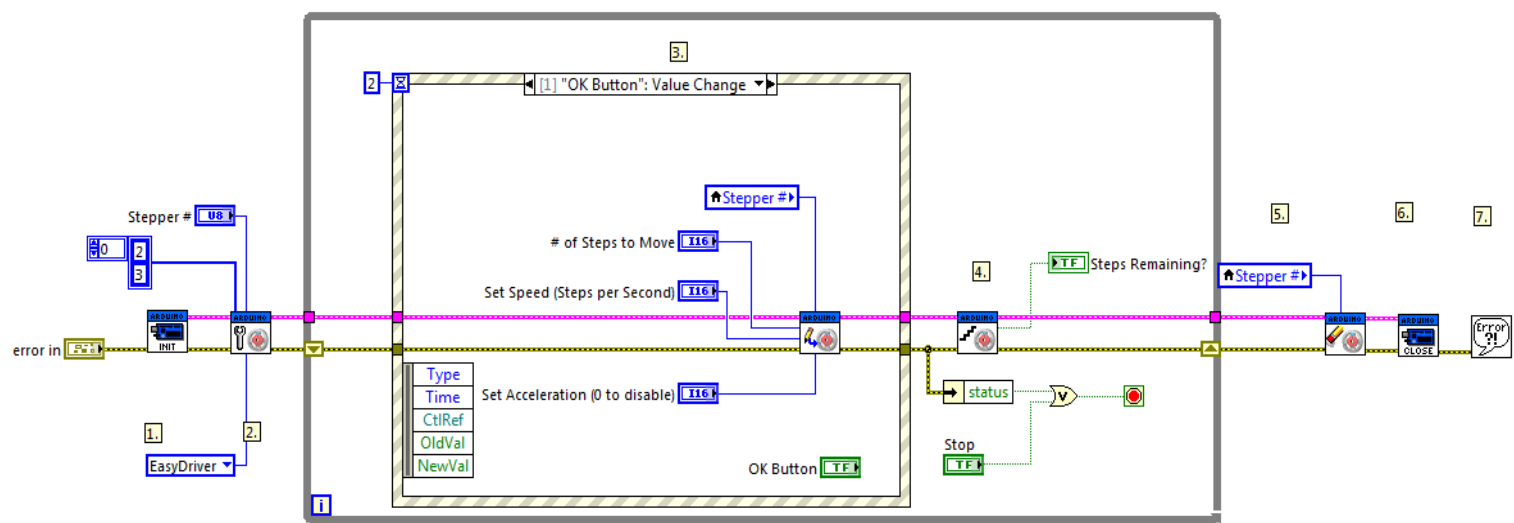

Figure (1.8) Control Panel of Stepper Motor in LabVIEW

A. Model without controller.

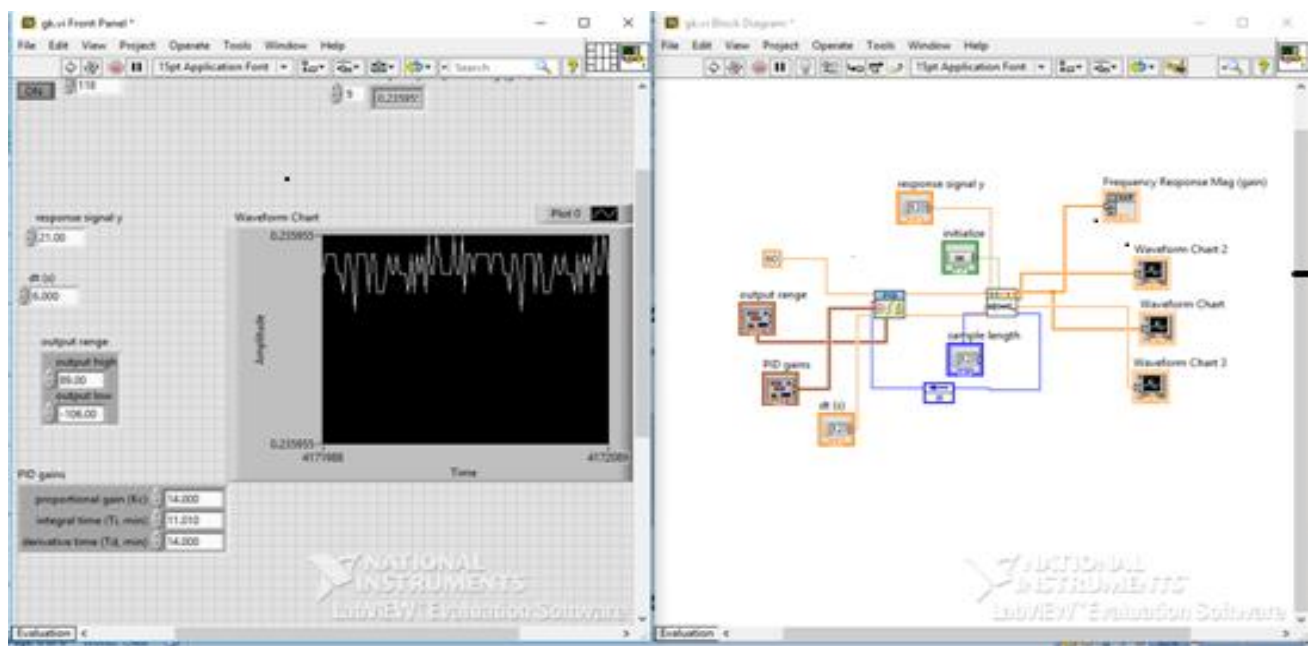

Figure (1.9) LabVIEW Simulation Output Without Controller

In LabVIEW the simulation output is obtained with harmonics in without controller. 
International Journal of Innovative Research in Electrical, Electronics, Instrumentation and Control Engineering

Vol. 7, Issue 5, May 2019

B. Bridge Circuit Model

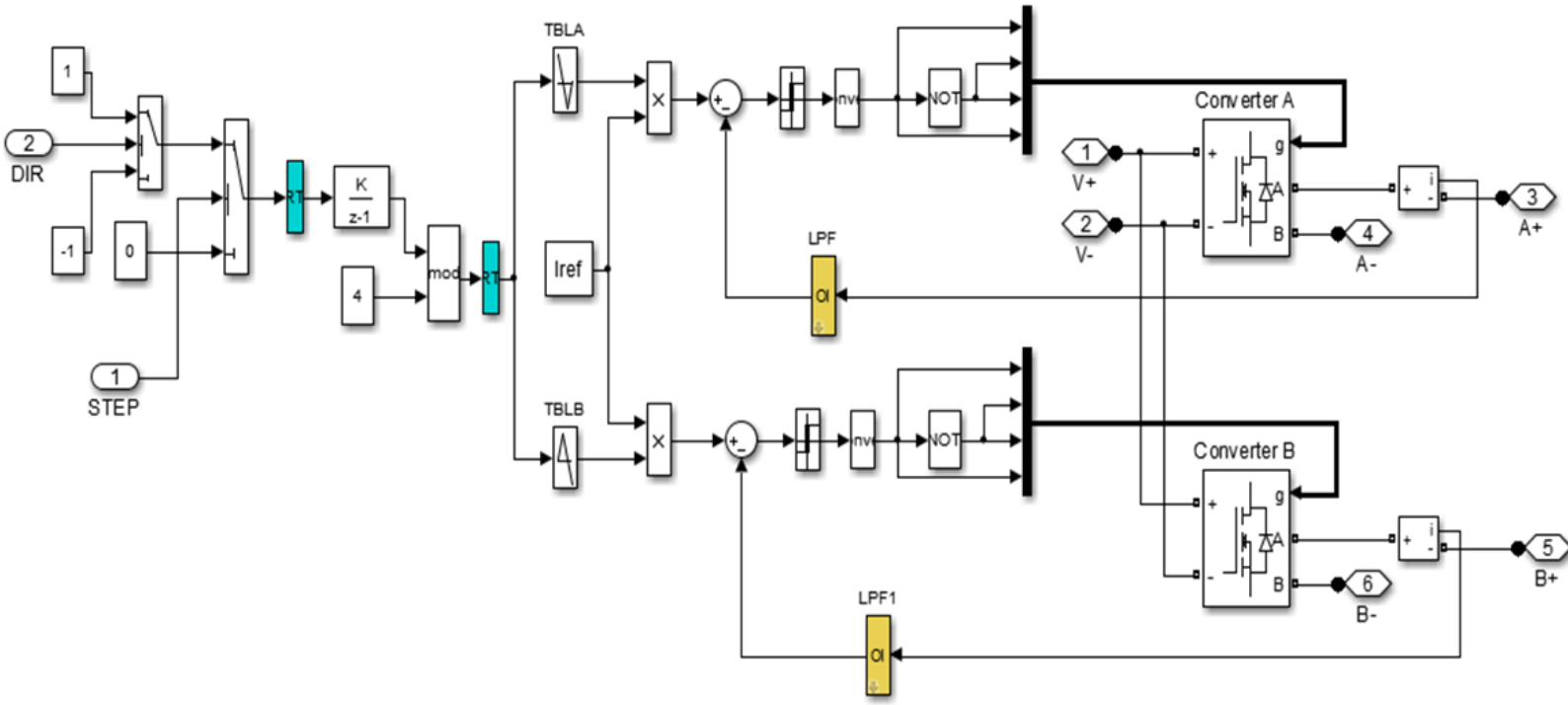

Figure(1.10) Bridge circuit model

C. LABVIEW Model with Controller

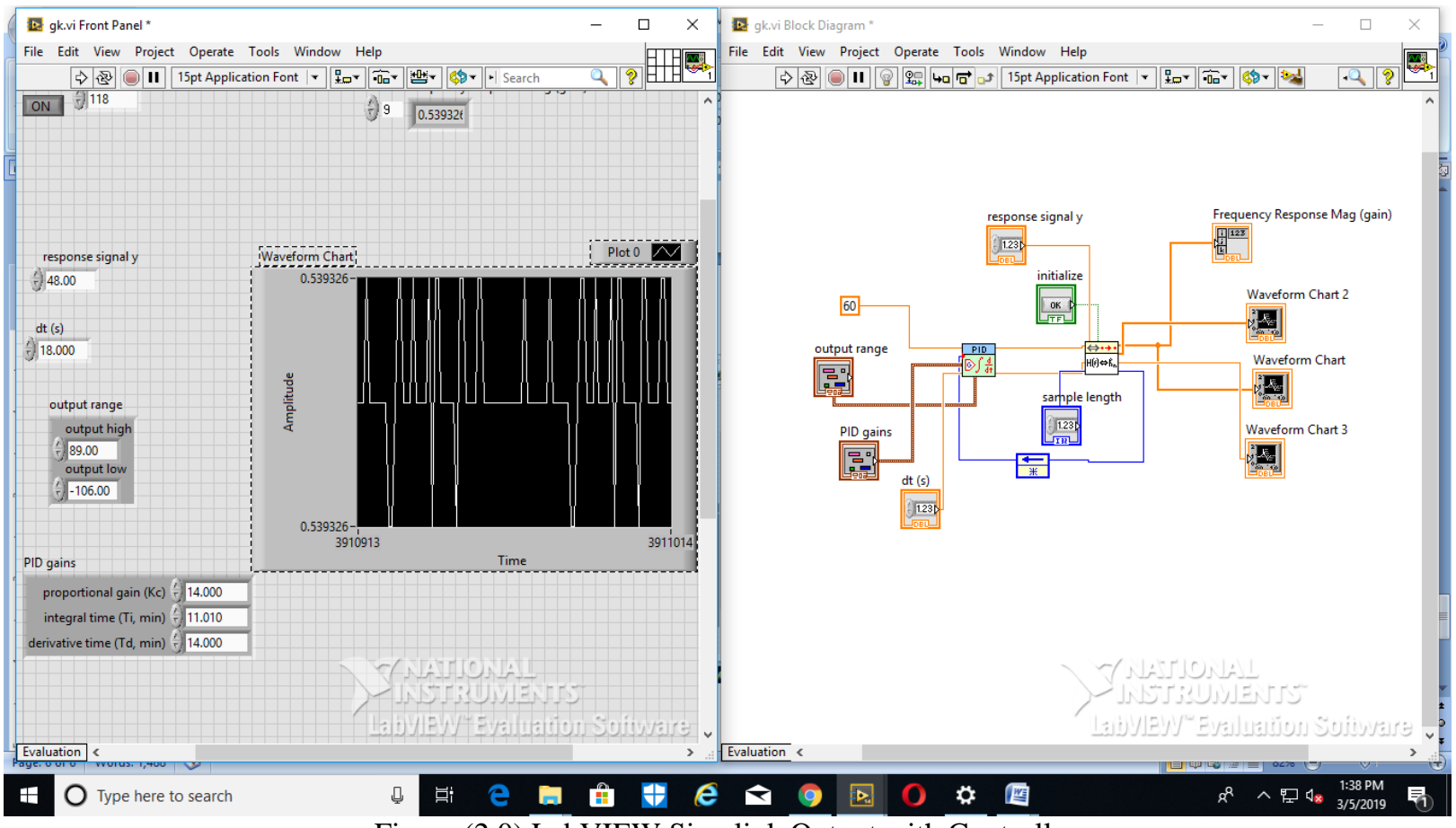

Figure (2.0) LabVIEW Simulink Output with Controller

In labview the simulation output is obtained in with controller. Here the ripples are reduced. 


\section{IJIREEICE \\ International Journal of Innovative Research in Electrical, Electronics, Instrumentation and Control Engineering}

Vol. 7, Issue 5, May 2019

\section{CONCLUSION}

In this paper the proposed Hybrid stepper motor is successfully modelled, and the output of the motor is controlled with the designed controller. Initially the parameters of the motor are taken into the Matlab platform, through which the system and controller are designed. The LabVIEW platform interfaced Arduino acts as a hardware tool for controlling the motor. The controller designed through Matlab is used in LabVIEW for controlled response.

\section{REFERENCES}

[1]. M.K Jenkins, D. Howe, and T.S. Birch, “An Improved Design Procedure for Hybrid Stepper Motor,” IEEE Transactins on Magnetics, vol. 26, No.5, Septmber 1990

[2]. M.jayalakshmi, G Asha and K Keerthana, Control of Single phase Z Source Inverter Fed Induction Motor Using Simple Boost Controlller ,International Journal of Emerging Trends in Electrical and Electronics, Vol 10, Issue 10, pp.44-48,2014.

[3]. K.R. Rajagopal, M.Krishnaswamy, Bhim Singh, B.P Singh, “An Improved High-Resolution Hybrid Stepper Motor for solar- Array Drive of Indian Remote-Sensing Satellite”, IEEE Transactions on Industry Applications, vol. 33, No.4. July/August 1997.

[4]. P.Asokan Kannan Govindan, R.Balasundaram, N.Baskar, A hybrid approach for minimizing makespan in permutation flowshop Scheluding, journal of Systems Science and Systems Engineering, Vol.26(1), 50_76,2017.

[5]. Petar Cmosija, Branislav and Stipe Ajdukovic, "Microcomputer Implementation of Optimal Algorithm for Closed-Loop Control of Hybrid Stepper Motor Drives", IEEE Transcations on Industrial Electronics, vol. 47, No. 6, December 2000.

[6]. Wonhee Kim, CHuan Yang, and Chung Choo Chung, "Design and Implementation of Simple Field-Oriented Control for Permanent Magnet Stepper Motors Without DQ Transformation”, IEEE Transactions on Magnetics, Vol. 47, No. 10, October 2011.

[7]. Dr.D.Srinivasan, B. RadhaKrishnan, M.Ramesh, R.Giridharan and R.Sanjeevi, DESIGN AND ANALYSIS OF MODIFIED IDLER IN DRAG CHAIN CONVEYOR, International Journal of Mechancial Engineering and Technology (IJMET), Volume 9, Issue 1,January 2018, pp.378-387.

[8]. Alessandro Masi, et.al, "An Application of the Extended Kalman Filter for a sensorless Stepper Motor Drive Working With Long Cables", IEEE Transaactions on Industrial Electronics, Vol. 59, No.11, November 2012.

[9]. Mark Butcher, et.al, "Hybrid Stepper Motor Electrical Model Extensions for Use in Intenlligent Drives", IEEE Transactions on Industrial Electronics, Vol.61, No.2, Febrauary 2014.

[10]. Youngwoo Lee, et.al, "Nonlinear H2 Control for a Nonlinear Sysstem with Bounded Varying Parameters: Application to PM Stepper Motors", IEEE/ASME Transactions on Mechatronics, Vol.22, No.3, June 2017.

[11]. Druti Ranjan Gaan, Manoj Kumar, and S. Sudhakar, "Real-Time Precise Position Tracking with Stepper Motor Using Frequency Modulation Based Microstepping”, IEEE Transactions on Industry Applications, Vol.54, No.1, January/Febrauary 2018.

[12]. Vincent Groenhuis and Stefano Stramigioli, "Rapid Prototyping High-Performance MR Safe Pneumatic Stepper Motors", IEEE/ASME Transactions on Mechatronics, Vol.23, No.4, August 2018.

[13]. Antoni Arias, et.al, "Reducing the cogging Torque Effects in Hybrid Stepper Machines by means of Resonant Controllers", IEEE Transactions on Industrial Electronics, Vol.66, No.4 April 2019.

[14]. Ying Wei, Yonghua Chen, Yang Yang, and Yingtian Li, "Novel Design and 3-D Printing of Nonassembly Controllable Pneumatic Robots", IEEE/ASME Transactions on Mechatronics, Vol.21, No.2, April 2016. 